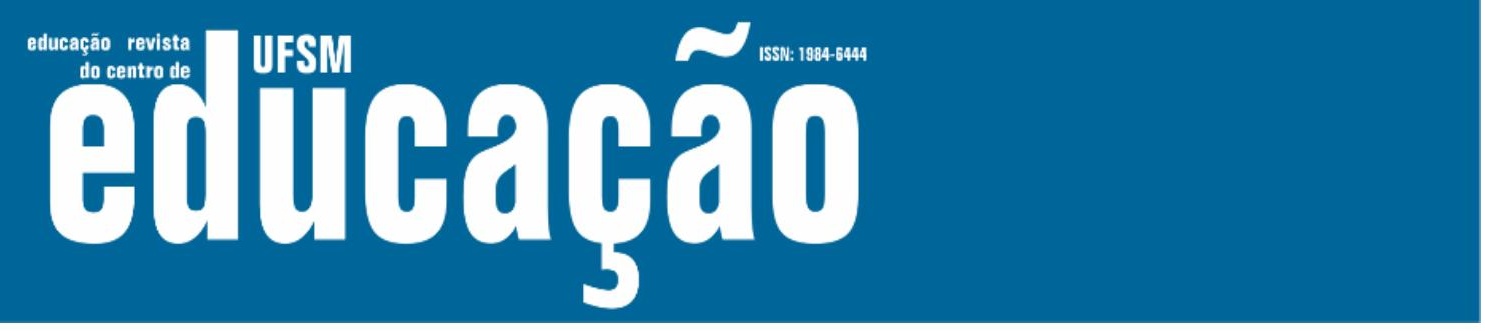

ISSN: 1984-6444 | http://dx.doi.org/10.5902/1984644439468

\title{
Para além de "meninas vestem rosa, meninos vestem azul": As conjunturas e as ideologias nos novos rumos da educação para os gêneros e as sexualidades
}

Beyond "girls wear pink, boys wear blue": the conjunctures and ideologies in the new rumps of education for genders and sexualities

Fabiana Aparecida de Carvalho

Professora doutora na Universidade Estadual de Maringá. Maringá, Paraná, Brasil.

facarvalho@uem.br - http://orcid.org/0000-0002-6746-4200

Recebido em 09 de agosto de 2019

Aprovado em 03 de setembro de 2019

Publicado em 18 de novembro de 2020

\section{RESUMO}

Este ensaio questiona as conjunturas contemporâneas das pautas de diversidade e promove uma genealogia de condições políticas e acontecimentais que favoreceram o ordenamento de um novo panorama na educação para os gêneros e para as sexualidades no Brasil, considerando, especialmente, as últimas três décadas. As análises, derivadas de leituras documentais, de revisões e de teorizações advindas das epistemologias feministas e pós-críticas, têm em vistas os gêneros e as sexualidades como dispositivos de poder e ferramentas para a compreensão das contradições sociais. Percorre as batalhas políticas de (des)construção das agendas destinadas à promoção de igualdade e equidade, entre elas, as interferências no Plano Nacional dos Direitos Humanos, o veto ao Brasil Sem Homofobia, o engessamento do Plano de Educação; questiona a ascensão fundamentalista religiosa e o recrudescimento de setores neoliberais e conservadores quanto à reiteração de discursos enviesados, preconceituosos e promotores de violências que podem afetar e normatizar a educação sexual.

Palavras-chave: Educação para os gêneros; Sexualidades; Discursos biológicos; Discursos religiosos.

\section{ABSTRACT}

This essay questions the contemporary conjunctures of diversity issues and promotes a genealogy of political conditions and events that helped the ordering of a new aspect in education for the genders and sexualities in Brazil, considering, especially, the last three decades. This research, derived from documentary readings, reviews and theorizations of feminist and post-critical epistemologies, have gender and sexuality views as instruments of power and help understanding social contradictions. The 


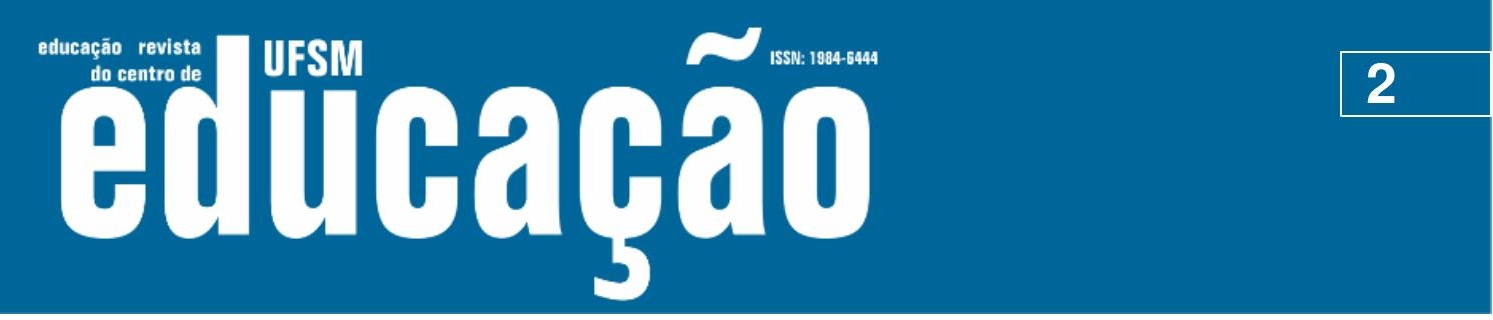

ISSN: 1984-6444 | http://dx.doi.org/10.5902/1984644439468

article analyzes the political battles of deconstruction of the agendas destined to the promotion of equality and equity, among them, the interferences in the National Plan of Human Rights, the suspension to Brazil Without Homophobia, the stagnation of the Education Plan; questions the religious fundamentalist rise and the upsurge of conservative and neoliberal sectors that is regarding the reiteration of skewed, prejudiced and violent discourses that can affect and normalize education for sexualities.

Keywords: Education for genders; Sexualities; Biological discourses; Religious discourses.

\section{Introdução}

Em janeiro de 2019, após o processo eleitoral que elegeu Jair Bolsonaro (PSL) como presidente do Brasil para o período de 2019-2022, a pastora Damares Alves, nomeada Ministra da Mulher, Família e Direitos Humanos na pasta oficial responsável pela reestruturação das políticas em prol dos direitos e da diversidade social, proferiu uma declaração afirmando ser contrária a uma "Ideologia de Gênero" circulante nas escolas, nas redes sociais e nos locais de produção de artefatos pedagógicos e educacionais. Damares declarou que seu mandato à frente do Ministério guiar-se-ia pelo resgate dos valores morais e por uma nova era na educação sexual das crianças, proferindo o bordão essencialista cunhado no fundamentalismo religioso de grupos católicos e neopentecostais: "meninos vestem azul e meninas vestem rosa1".

$\mathrm{Na}$ ocasião, Damares enunciou também parte da posição teísta do novo governo. Somada a essa configuração, a base política na gestão atual está fortemente atrelada à promoção do Estado mínimo, ao enxugamento de investimentos públicos nas áreas prioritárias como saúde e educação e à convicção ideológica da existência de uma guerra cultural entre a direita liberal e uma facção esquerdo-partidária que visa, sobretudo, impor-se no âmbito da sociedade civil, tornando-se dominante nas pautas sócio- assistenciais manifestas nos ministérios, nas escolas, universidades e nos locais de produção do conhecimento. Tal viés deliberadamente assinala, conforme apontam Denise Carreira e Roberto Catelli, a existência de um "movimento em curso na gestão educacional comprometido com a desconstrução ampla e profunda das políticas educacionais como direito humano" (CARREIRA, CATELLI, 


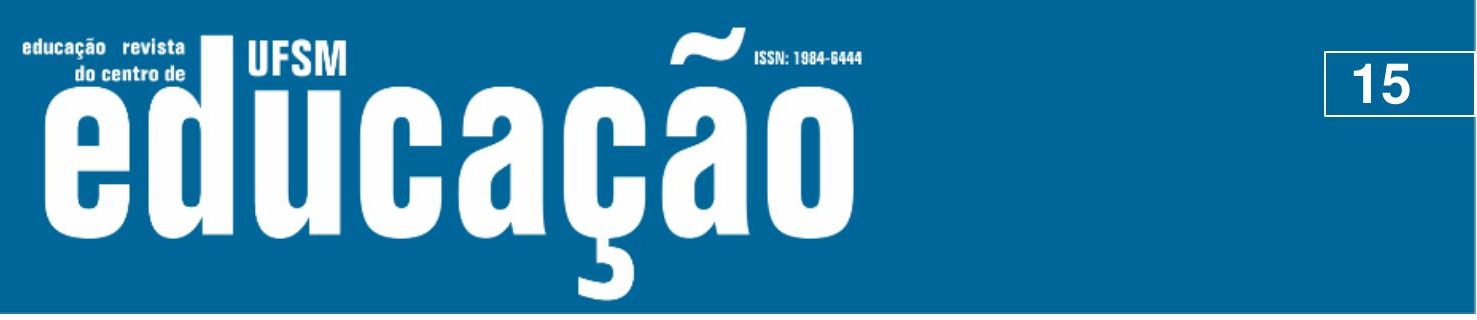

ISSN: 1984-6444 | http://dx.doi.org/10.5902/1984644439468

um campo contraditório de investidas para se controlar e se normatizar os corpos, os prazeres, as questões de gênero sempre em função de uma sociedade que exclui aquilo que ela mesma patologiza e não deseja. Com o efeito de um dispositivo de sexualidade, ou, de verdade [...], o deslocamento e a invisibilidade semântica tanto do termo gênero, quanto dos termos raça, etnia e orientação sexual, nos [...] planos educacionais [...], não favorecem a uma política de erradicação da violência de gênero nas escolas. Discursivamente, portanto, tem-se um jogo de apagamentos e de contradições entre poderes, resistências, necessidades que derivam da implantação das políticas públicas e educacionais sobre gênero e violência de gênero. Em meio à urgência das necessidades sociais e das políticas de proteção, combate e visibilidade dos direitos de mulheres, crianças e minorias, esse dispositivo (quer seja na forma de lei, quer seja nos preconceitos e desconhecimentos internalizados pelos diferentes setores sociais) impede aquilo que, formativamente, deveria visar, ou seja: a educação para a sexualidade e o respeito ante a diversidade cultural e sexual no Brasil (CARVALHO et al, 2015, p. 103).

De fato, os muitos episódios dos planos de educação no país desvelaram que as ações parlamentares, além de repressoras, sexistas, misóginas e segregadoras, foram ações subsidiadas por biopoderes porque, juridicamente, importaram-se em classificar e correlacionar as sexualidades a uma biologia do nascimento e "à noção de continuidade entre sexo - gênero - desejo - prática sexual" (CARVALHO; POLIZEL; MAIO, 2016, p. 81) aos entendimentos perpassados pela ideia de direito/lei natural, ou seja, por uma concepção amparada por dispositivos religiosos que não reconhecem feminilidades e masculinidades como constructos ligados às estruturas sociais, ao machismo, ao patriarcado e aos processos de apagamento da diversidade cultural e sexual.

Ainda em 2014 e 2015, o Movimento Brasil Livre (MBL) e a organização Escola sem Partido (ESP) interpelaram o Instituto Nacional de Estudos e Pesquisas Educacionais Anísio Teixeira (INEP) quanto à presença de questões referentes a temas sociais contundentes no Exame Nacional do Ensino Médio (ENEM), tais como: violência contra mulheres, feminícidio, expropriação da força de trabalho e regimes de escravidão social. Os movimentos alegaram a contaminação do ENEM com proposições marxistas e sociológicas, com preleções feministas, ideológicas, com ofensivas aos valores tradicionais cristãos e com a exigência de respostas para além do conhecimento científico e do conhecimento escolar das áreas de história, de filosofia, sociologia e mesmo biologia. 


\section{F WEM Eltónato

ISSN: 1984-6444 | http://dx.doi.org/10.5902/1984644439468

conservadores religiosos e sociais tem incorrido, justamente, no mascaramento histórico e na inversão dos avanços sócio-educacionais em relação aos gêneros, às sexualidades e às diferenças, para se criar o establishment e a genealogia dessa categoria política e reacionária: a Ideologia de Gênero (GARBAGNOLI; PREARO, 2017; JUNQUEIRA, 2017), assim como de sua ênfase em rebater diretamente as epistemologias feministas e as militâncias LGBT por serem essas os contrapontos não hegemônicos em relação às conquistas e à paridade de direitos sociais.

\section{A evolução da (des)montagem das políticas públicas educacionais para os gêneros e as sexualidades nas últimas décadas}

Essa concepção de Teoria ou Ideologia de Gênero não é fato ou ideia recente. Seu histórico desponta, inicialmente, na década de 1990, quando Barbara Dale O'Leary, jornalista cristã coligada ao prelado Opus Dei, fora incumbida pelo Vaticano de cobrir a Conferência para as Mulheres de Pequim. Nesse momento, a Organização das Nações Unidas (ONU) exortava os gêneros como ferramentas na superação de desigualdades e para o tratamento igualitário destino às mulheres e às pessoas LGBT pertencentes a países e lugares em condições de baixo desenvolvimento e risco social. O'leary, entretanto, apregoou essa tomada de decisão como um conluio internacional de forças de esquerda destinado a corromper os setores públicos e privados, principalmente com fins de destruição da família e de corrupção de crianças e jovens.

Esse posicionamento canônico contagiou a visão de representantes eclesiásticos nas duas últimas décadas, como exemplo: o Cardeal Ratzinger, feito Papa Emérito Bento XVI, o bispo da cidade Lima, Monsenhor Oscar Revoredo, o padre e psicanalista romano Tony Anatrella, a teóloga Marguerite Peeters, o argentino Jorge Scala e o jurista brasileiro Ives Gandra Martins, também partidário da Opus Dei (AUTOR, 2017; GARBAGNOLI; PREARO, 2017). O "Documento da Aparecida" (CELAM, 2007), expedido pela Igreja Católica, fulgura na América Latina e no Brasil como um apelo fundamentalista contra a ideia de Ideologia de Gênero, orientando canonicamente que entre 


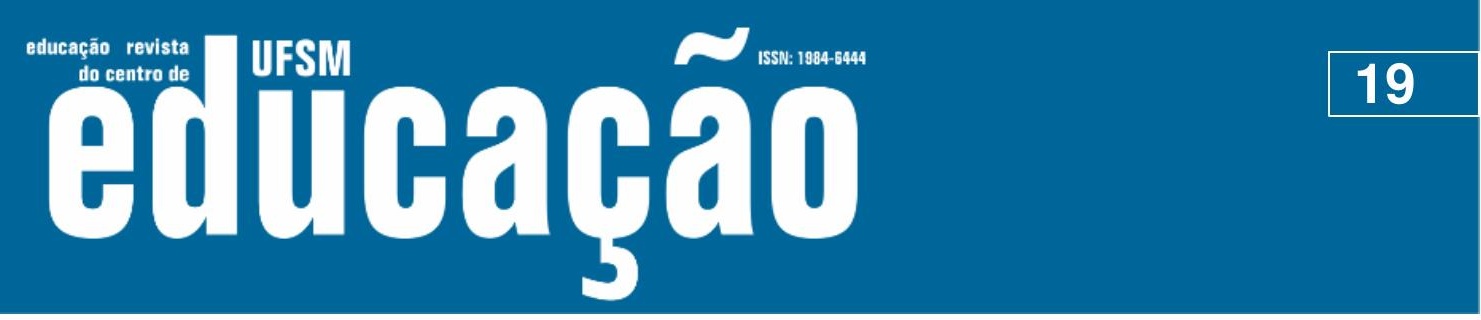

ISSN: 1984-6444 | http://dx.doi.org/10.5902/1984644439468

os pressupostos que enfraquecem e menosprezam a vida familiar encontramos a ideologia de gênero, segundo a qual cada um pode escolher sua orientação sexual, sem levar em consideração as diferenças dadas pela natureza humana. Isto tem provocado modificações legais que ferem gravemente a dignidade do matrimônio, o respeito ao direito à vida e a identidade da família (CELAM, 2007, p. 08).

O documento pensa as políticas públicas de gênero em termos de um cenário anticristão despótico e como regras poluídas por ideários que disseminam o controle populacional, a liberdade sexual, o aborto a qualquer custo, a ideia de modificação/redesignação sexual dos corpos, o ativismo gay, lésbico e transgênero, o casamento para todas/os e a multiplicidade de vivências afetivas como questões de escolhas individuais inventadas a bel prazer e cambiáveis a qualquer momento.

Nessa perspectiva, a lgreja tem insistido em distorcer as pautas de gênero da ONU e das epistemologias feministas com base em mais outras duas formações discursivas: a) a de que a organização desejaria implantar ideários feministas e gayzistas em escala planetária; b) a de que os estudos de gênero têm saído do plano acadêmico e migrado para as escolas para ganhar um corpo ideológico de colonização com métodos doutrinários de convencimento que se baseiam - única e exclusivamente - na imposição das vontades ditatoriais LGBT às/aos jovens. A base da discursividade católica foi paulatinamente assumida pelas igrejas neopentecostais brasileiras a partir dos anos de 2000, e essas conclamam, na conjuntura política atual, a palavra de deus e a interpretação literal dos preceitos bíblicos de normatividade sexual numa massiva investida contra os princípios laicos do Estado.

Num processo viralizante de politização desses discursos religiosos, o Vaticano recorre veementemente a exortações apostólicas e a encíclicas para reafirmar que "projetos educativos e diretrizes legislativas" [...] promovem uma identidade pessoal e uma intimidade afetiva radicalmente desvinculadas da diversidade biológica entre homem e mulher" (LAZARI, 2016, p. 122). Sustentado pela demonização das pessoas LGBT, o dispositivo anti-gênero dessa suposta Ideologia cruza-se ainda com outros dispositivos complementares: a reformulação eufemística da ordem sexual a partir de ideias de feminilidade e de orientação sexual e a apresentação de argumentos de autoridade advindos da manipulação dos saberes científicos como verdades inquestionáveis. 


\section{تilloapẫ}

ISSN: 1984-6444 | http://dx.doi.org/10.5902/1984644439468

dois sexos na natureza: homem e mulher", "meninos vestem rosa e meninos vestem azul", repetidos à exaustão em pronunciamentos e dispositivos pedagógicos religiosos, dispensam-se os marcadores culturais de nossas personalidades, desejos e condutas por intermédio de uma biologia decalcada de algum compêndio não apenas como a base redutivista de uma interpretação arbitrária, mas como bloqueio das possibilidades de intervenção ativa, emancipatória e transformadora, que foram "postas em prática por conceitos feministas de gênero como diferenças localizadas socialmente, historicamente e semioticamente" (HARAWAY, 1995, p. 35).

Nessa manifestação da Igreja, os princípios jurídicos tornam-se bem mais difusos e os sexos biológicos são vistos como distintivos na constituição do Estado e para se negociar equitatividade entre os grupos sociais; todas as demais manifestações das sexualidades ou dos gêneros a descaracterizar esse princípio básico, segundo o legado canônico, seriam, pois, antibiológicas, antinaturais e desenvolvidas por experiências negativas e pecaminosas. Como desvios de conduta, poderiam ser estudadas, analisadas à exaustão, etiquetadas e corrigidas, sobretudo, porque se acredita na natureza cisgênera (de equivalência da condição biológica do sexo e com a manifestação cultural do gênero) e heterossexual.

As epistemologias feministas consideram preocupante essa potencialização dos saberes teológicos e dos dispositivos anti-gêneros para se legitimar a ordem sexual patriarcal e heterocentrada da natureza, já que o Vaticano busca substituir a linguagem do gênero pela do sexo natural (BUTLER, 2014), rebiologizando a diferença sexual e estabelecendo um estreitamento do conceito de reprodução como um destino social que vai desde a certidão de nascimento até as políticas públicas estatais-.

Esse é um exemplo do uso distorcido das ciências para produzir sentidos, compreensões e significados científicos, culturais e políticos equivocados na cabeça das pessoas leigas. A questão é que 


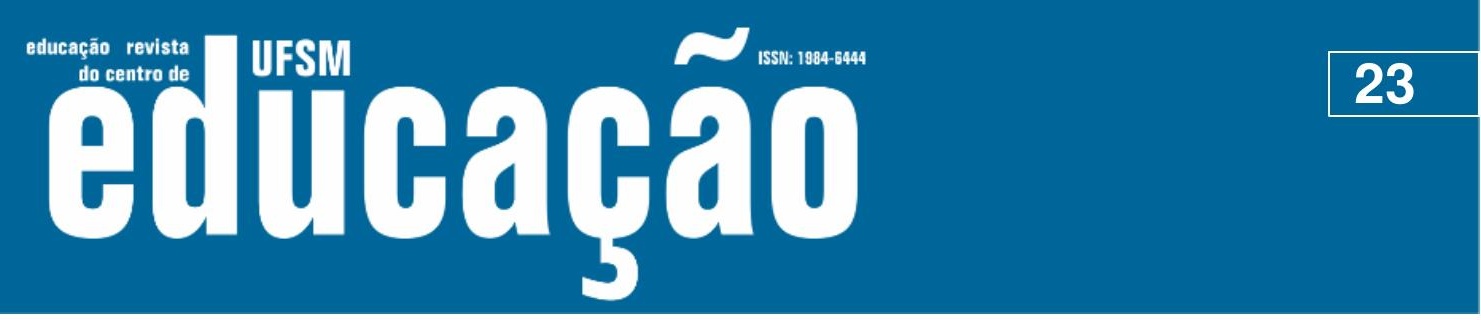

ISSN: 1984-6444 | http://dx.doi.org/10.5902/1984644439468

Atualmente, acolhida no sintagma Ideologia e nos comunicados destinados às pessoas fiéis emitidos pelo Papa Francisco, a polaridade dos gêneros é a base jurídica da negação das pessoas LGBT pela Igreja que, gradativamente, povoa os sentidos das explicações que adensam as escolas.

Muito embora os catecismos tenham reconhecido o papel humano da acolhida às pessoas homossexuais e transgêneras, o Vaticano nega-lhes o direito ao casamento e à união civil, pois reconhece que o matrimônio de pessoas do mesmo gênero: a) "evoca temores com relação à sobrevivência da instituição em seu papel de mantenedora de toda uma ordem social" (MISKOLCI, 2007); b) desestabiliza o dogma do pecado original, que prescinde justamente da existência dos sexos/gêneros complementares para a igreja exercer/impor seus sacramentos; c) requer a rediscussão do direito à herança e à propriedade a partir do próprio poder eclesial; d) exige o reconhecimento dos diferentes arranjos afetivos e familiares; e) exige a aceitação da homo-lesbo-parentalidade e da adoção diferenciada; f) força a aceitação de questões ligadas à reprodução artificial e às redesignações corporais de gênero para atender aos direitos sociais, reprodutivos e individuais das pessoas. $E$ mais: incisivamente, os catecismos consideram as condutas dissidentes como depravações, distorções da natureza e atos intrinsecamente desordenados das condutas humanas (VATICAN, 2017). Passíveis de serem estudadas e vigiadas, as pessoas LGBT se subordinariam à castidade incondicional para se restringirem a uma homossexualidade bem comportada e silenciosa.

Consonante a esse empreendimento do pensamento dogmático, a Congregação para a Educação Católica formalizou, no mês de julho de 2019, e o Papa Francisco endossou um manual cristão sobre o gênero nas escolas denominado: "Homem e mulher Ele os criou: rumo a um caminho de diálogo na questão da teorida de gênero na educação" (VATICAN, 2019), cujo objetivo é orientar as discussões escolares sobre sexualidade e diversidade de forma metódica, com base em pesquisas científicas consideradas relevantes pela igreja e não alinhadas às teorias feministas e aos estudos de gênero. Esse documento não retira a educação para as sexualidades e para a diversidade das escolas, ao contrário, ele visa manter a orientação cristã sobre os corpos, as orientações afetivas, as vivências sexuais 


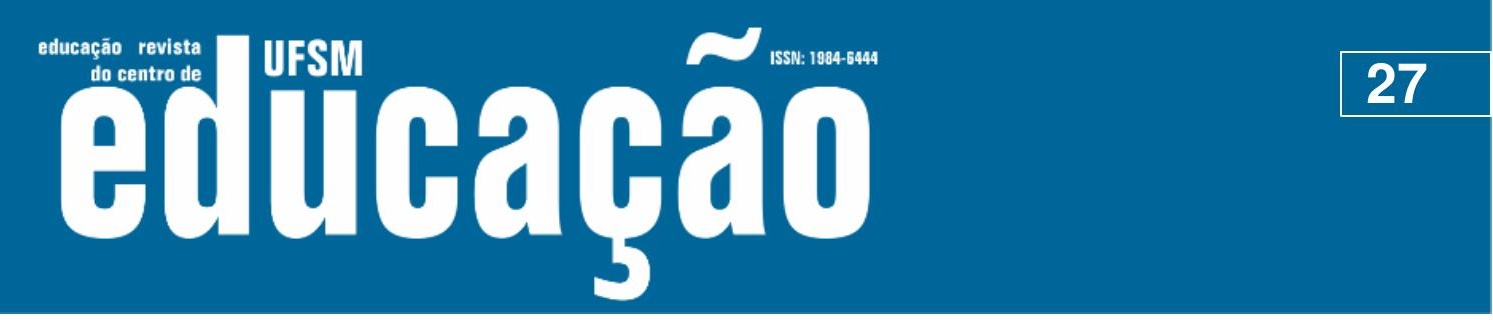

ISSN: 1984-6444 | http://dx.doi.org/10.5902/1984644439468

Obstinadamente, setores políticos e religiosos seguem com o apelo de retirada dos gêneros nas escolas, mas nenhuma escola tem o poder de mudar ou de extinguir os gêneros e as orientações afetivas de cena; por mais que se perpetrem violências e apagamentos simbólicos, as pessoas continuarão a clamar por suas marcas identitárias, por novas conjecturas de Educação Sexual e por posicionamentos libertários que desestabilizam a ordem social classista, hierárquica e preconceituosa.

\section{Referências}

BEAUVOIR, Simone. O segundo sexo. 2ª ${ }^{\text {a }}$ ed. Rio de Janeiro: Nova Fronteira, 2009. BIROLI, Flávia. Gênero e desigualdades - limites da democracia no Brasil. São Paulo: Boitempo, 2018.

BRASIL. Secretaria de Educação Fundamental. Parâmetros curriculares nacionais: apresentação dos temas transversais. Brasília, 1999.

BRASIL. Conselho Nacional de Combate à Discriminação. Brasil Sem Homofobia. Brasília: Ministério da Saúde, 2004.

BRASIL. Decreto no 9.759, de 11 de abril de 2019. Extingue e estabelece diretrizes, regras e limitações para colegiados da administração pública federal. Disponível em: http://www.planalto.gov.br/ccivil_03/_ato2019-2022/2019/decreto/D9759.htm. Acesso em: 31 mai. 2019.

BUTLER, Judith. Undoing gender. Nova York: Routledge, 2004.

BUTLER, Judith. Problemas de Gênero. Rio de Janeiro: Civilização Brasileira, 2003.

CARREIRA, Denise; CATELLI-JÚNIOR, Roberto. Educação: a mediocridade autoritária como política de governo. In: AÇÃO EDUCATIVA. Educação em disputa: 100 Dias de Bolsonaro. São Paulo: Ação Educativa, 2019. p. 07-09.

CARVALHO, Fabiana Aparecida de. Os discursos biológicos para os gêneros - as sexualidades e as diferenças: aproximações e distanciamentos. 2018, 223f. (Tese de Doutorado) - Programa de Pós Graduação em Educação para a Ciência e a Matemática, Universidade Estadual de Maringá, Maringá, 2018.

CARVALHO, Fabiana Aparecida de et al. Políticas públicas e (in) visibilidades escolares: entre (des)conhecer, apagar e trabalhar com o combate à violência de gênero. In: CORREA, Crishna Mirella Andrade; MAIO, Eliane Rose (Orgs.). Observatório de violência de gênero: entre políticas públicas e práticas pedagógicas. Curitiba: CRV, 2015. p. 99-115. 


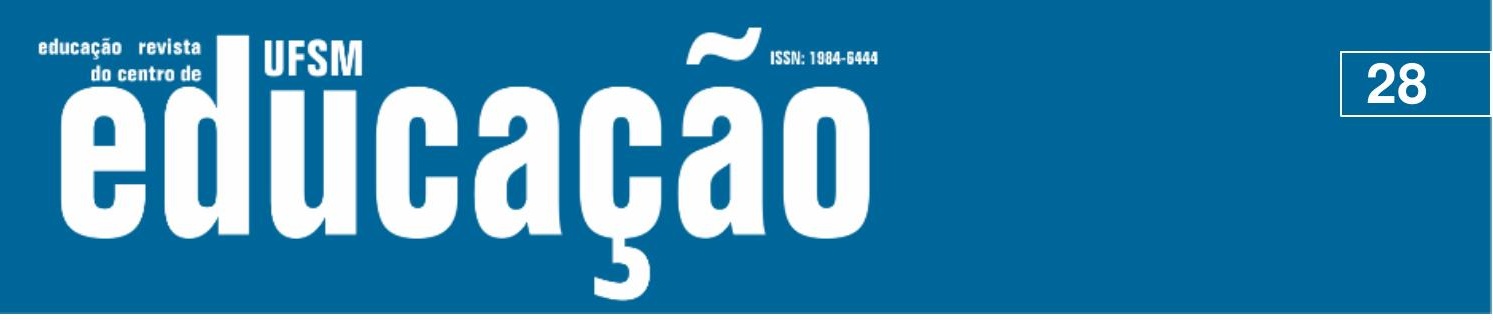

ISSN: 1984-6444 | http://dx.doi.org/10.5902/1984644439468

CARVALHO, Fabiana Aparecida de; LORENCINI-JÚNIOR, Álvaro. Os discursos biológicos para os gêneros, as sexualidades e as diferenças no Brasil: um panorama histórico. Revista Valore, Volta Redonda, nº 3 , p. 575-586, 2018.

CARVALHO, Fabiana Aparecida de; POLIZEL, Alexandre Luiz. Biopolíticas de negação ao gênero e ao Feminismo no Movimento Escola sem Partido. In: FAZENDO GÊNERO, XI, 2017, Florianópolis (SC). Anais [...]. Florianópolis: UFSC, 2017, p. 01 12.

CORREA, Crishna Mirella Andrade. Educação, lei e sexualidade: a importância da discussão sobre os padrões normativos do comportamento sexual e de gênero na escola. IN: MAIO, Eliane Rose; CORREA, Crishna Mirella Andrade (Orgs.). Gênero, direitos e diveresidade sexual: trajetórias escolares. Maringá: Eduem, 2013. p. 4354.

CELAM. Documento da Aparecida. 2007. Disponível em: https://www.franciscanos.org.br/wp-content/uploads/2012/05/docaparecida.pdf. Acesso em: 31 mai. 2019.

FERNANDES, André Gonçalves. Ideologia de gênero, transexualidade e retificação de assento. In: SILVA-MARTINS, Ives Gandra; BARROS-CARVALHO, Paulo de. (Orgs). Ideologia de Gênero. São Paulo: NOESES / UJCSP, 2016

FOUCAULT, Michel. Tecnologías del yo. Buenos Aires: Páidos, 2008.

FOUCAULT, Michel. A história da sexualidade I. 14르. ed. Rio de Janeiro: Graal, 1988.

FURLAN, Cássia Cristina; CARVALHO, Fabiana Aparecida de. Gênero: para além das disputas ideológicas, os amparos legais. In: OLIVEIRA, MÁRCIO de; MAIO, ELIANE ROSE (Orgs.). Gênero, sexualidades e diferenças: categorias de análise, (des)territórios de disputas. MARINGA: EDUEM, 2019. p. 61-82.

GARBAGNOLI, Sara; PREARO, Maximo. La croisade anti-genre. Paris: Textuel, 2017.

GENTILLI, Pablo A.; SILVA, Tomaz Tadeu da. Neoliberalismo, qualidade total e educação: visões críticas. Petrópolis: Ed. Vozes, 1994.

GONZÁLEZ, Rodrigo Stumpf. A política de promoção aos direitos humanos no Governo Lula. Revista Debates, Porto Alegre, v. 4, nº. 2, p. 107-134, Jul./Dez. 2010.

HARAWAY, Donna. Saberes localizados: a questão da ciência para o feminismo e o privilégio da perspectiva parcial. Cadernos Pagu, Campinas, nº. 5, p. 07-41. 1995.

JUNQUEIRA, Rogério Diniz. Ideologia de gênero: a gênese de uma categoria política reacionária. In: RIBEIRO, Paula Regina Costa; MAGALHÃES, Joanalira Corpes (Orgs.). Debates contemporâneos sobre educação para a sexualidade. Rio Grande: FURG, 2017. p. 25-52. 


\section{$\sim$

ISSN: 1984-6444 | http://dx.doi.org/10.5902/1984644439468

(c) $(1)(8$

This work is licensed under a Creative Commons Attribution-NonCommercial 4.0 International (CC BY-NC 4.0)

\section{Notas}

\footnotetext{
${ }^{1}$ Pronunciamento de Damares Alves sobre o combate à ideologia de gênero nas escolas brasileiras. Disponível em: https://oglobo.globo.com/sociedade/menino-veste-azul-menina-veste-rosa-diz-damares-alves-em-video23343024.

2 Palavras de Dilma Rousseff sobre a proibição do Programa Brasil sem Homofobia. Disponível em: http://g1.globo.com/educacao/noticia/2011/05/governo-nao-fara-propaganda-de-opcao-sexual-diz-dilma-sobrekit.html.

${ }^{3}$ Tradução minha: "falar a verdade ocultada do gênero para reiterar a verdadeira verdade do sexo como um fato da natureza".
} 